\title{
Theoretical Design and Computational Fluid Dynamic Analysis of Projectile Intake
}

\author{
Wei Wang \\ Science and Technology on Combustion, Internal Flow and Thermo-Structure Laboratory, \\ Northwestern Polytechnical University, Xi’an, China \\ midule@mail.nwpu.edu.cn \\ Likun Cui and Zhuo Li \\ College of science, Inner Mongolia University of Technology, Hohhot, China \\ lekuncui@sina.com and li_zhuo@263.net
}

\begin{abstract}
With the development of the science and technology, the more requirements such as cost effective, high specific impulse in wide operation rang, becomes stricter and multiplicity. However, the existing supersonic inlet can no longer adjust to all the new projectiles. In this paper, based on the basic characteristic of inlet and considering the design requirements, the two-dimensional supersonic projectile inlet was designed and verified by numerical simulation under different operating conditions such as attack angle, altitude, and so on. The results are shown that: 1) The design process is successful, but the working conditions should be limited to the small angle of attack; 2) The total pressure recovery coefficient is increasing as the Ma number increases, and then is gradually decreased after the point of Mach number is equal to 0.5 ; 3) The existence of attack angle reduces values of total pressure recovery. And moreover, the shock wave which occurs at the anterior point is gradually deviating from projectile body direction with the increase of attack angle; 4). The variance ratio in the outlet has the acute changed with increasing of altitudes clearly, but its corresponding values degrade sharply in the entrance.
\end{abstract}

Index Terms-supersonic air inlet, two-dimension, ramjet projectile, numerical simulation, influence factors

\section{INTRODUCTION}

With the development of the science and technology, the more requirements such as cost effective, high specific impulse in wide operation rang, becomes stricter and multiplicity. However, the existing supersonic inlet, which is the entrance channel of the solid rocket ramjet engine and plays a crucial role in assisted range performance, can no longer adjust to all the new projectiles. Thus this situation has led renews interest in the inlet design and performance validation. Researchers' studies and experiments have confirmed the theoretical operation and demonstrated the feasibility of the twodimensional inlet as an air supply system that meets those

Manuscript received: December 20, 2010; revised: March 17, 2011; accepted: May 10, 2011

Project: the Natural Science Fund of the Inner Mongolia

Autonomous Region Grant \#200508010705.

Corresponding author: Wei Wang. desires. The previous studies by some institutions at home and abroad revealed the potential to provide efficient and flexible airflow which the combustion requires [1-2].This interest in the supersonic projectile inlet encouraged our research team to proceed with design and verification of a new one.

This paper's study is carried out as a part of the wide research on solid rocket ramjet extended range projectile. So in following sections, a two-dimensional supersonic projectile inlet, which parameter selection must be carried out keeping in mind the number of stages and the overall projectile diameter, was designed and verified by numerical simulation under different operating conditions based on the basic characteristic of the inlet and considering the design requirement.

\section{INLET DESIGN}

It is well known that the effects of each factor such as flight altitude, attack angle, airflow, inlet Mach number of the combustion chamber, and so on, have been discussed respectively in many books and articles [3-5], but there is still some disagreement over important issues. In this section, we are concerned with design of supersonic flow in projectile intake base on classical theories and practice experiences. The majority work is determined of the design method in this period. At the end of the process, the Oswatisch design method is selected, and moreover, several design requirements, which list in Table I, have now been built to verify such a flow system under the conditions of considering various desires [6].

TABLE I.

PAPERS DESIGN REQUIREMENTS

\begin{tabular}{|c|c|}
\hline Parameter & Requirement \\
\hline Mach number of incoming flow & 3.50 \\
\hline Total pressure recovery coefficient & $>0.27$ \\
\hline Combustor inlet Mach number & $<0.40$ \\
\hline Inlet flow rate & $>2.0 \mathrm{~kg} / \mathrm{s}$ \\
\hline Inlet number & 4.00 \\
\hline
\end{tabular}


Of greater importance to the intake design is the shape of the inlet throat section and the initial diffuser expansion, so the conceptual design began with this selection.

\section{A. Shape design}

Having selected the parameters, the design steps are as follows:

1) Determining the capture area according to atmospheric parameters under design Mach number, flow and flight altitude;

2) Inlet adopted four-wave system, and distributed by using the principle of Oswatisch [7];

3) The next parameter required in the design is the flow coefficient under minimum working Mach number. This parameter is estimated by using the one-dimensional distributing wave theory in order to calculate the inlet capture flow and determine the initial throat area, and then previous design is modified according to results, which are attained by the numerical simulation;

4) Finally, the compression ratio [8] is determined and internal compression channel design is accomplished.

Considering to avoid total pressure loss occur due to friction and flow separation, which caused by shocks in the interior of the inlet, the authors have tried to use low gradient dilated segment where possible and given the optimization turn radius, so it changed slowly along the flow direction [3]. In addition, variable-width design method which expansion semi-angle is around three degrees makes it easy to meet the exit Mach number requirement. Early inlet configurations are evaluated approximately using two-dimensional (2D) computational fluid dynamics (CFD) techniques, with the final inlet configurations analyzed in the analysis in the three dimensions (3D), and the ultimate schematics are shown in Fig. 1.
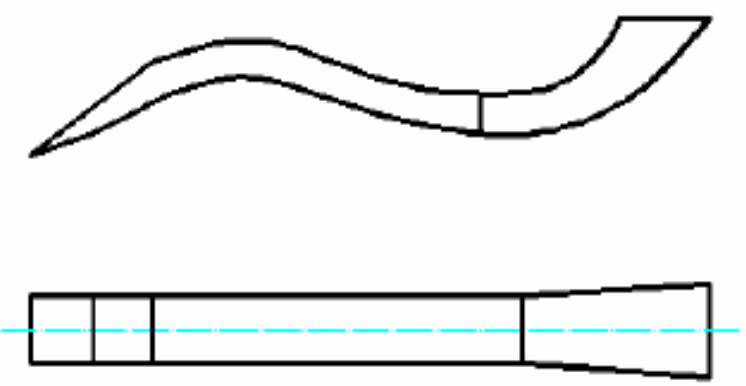

Figure 1. Schematic diagram of inlet

\section{B. Arrangement}

For this study, the number of inlets is four which is desired by the design requirements. In order to show the inlets' arrangement, Fig. 2 gives the overall schematic of solid rocket ramjet assisted range projectile. It is well clear that the four inlets symmetrical distribution in after the body and the distributing shape is ' $X$ '. This arrangement is admittedly somewhat experiential and many modifications in the future as the further mission requirement is redefined. It should be of special note is that this selection is made under an assumption that projectile does have slight angle of attack requirements.

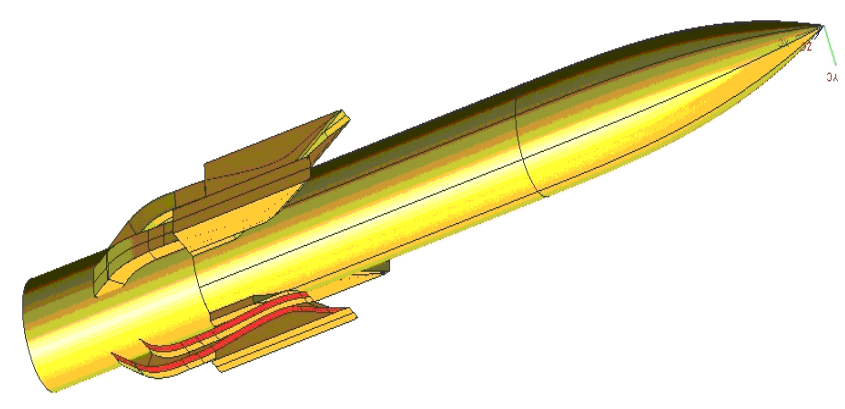

Figure 2. Projectile overall schematic

However, there is still no idea about the design validity, so the authors will examine and analyze the inlet performance in the following sections in order to prove this point.

\section{PROBLEM Formulation}

Considering the complexity of the flow within a projectile inlet, involving compressible flow, shock interactions and turbulent, had led to increasing reliance on CFD as a tool to obtain performance parameters [9]. It's very known that the computation methods must be choosing carefully in order to gain credible data from the numerical computation, so the next paragraphs will discuss them in detail.

\section{A. Navier-Stokes equation}

Compressible flow within the intake is modeled using Navier-Stokes equation, which is given by Eq. (1), based on the conservation of mass, momentum and energy [10].

$$
\frac{\partial}{\partial t} \iiint_{V} \bar{Q} d V+\iiint_{\partial V} \bar{F} \cdot n d S=0
$$

Where $\bar{F}$ is vector flux, $n$ is outer normal vector of boundary, $\partial V$ is boundary of a fixed region, $\bar{Q}$ is conservation vector and its expression is shown in Eq. (2):

$$
\bar{Q}=(\rho, \rho u, \rho v, \rho w, \rho e)^{T}
$$

Where $\rho$ air density of per mass air, $(u, v, w)$ are three components of the velocity under the Cartesian coordinates, $e$ is total energy of per mass air and its expression is shown in the follow equation:

$$
e=\frac{p}{(\gamma-1) \rho}+\frac{u^{2}+v^{2}+w^{2}}{2}
$$

Due to expense of each CFD solution, the relative merit of two techniques for solves the compressible flow equations, namely the pressure based Navier-Stokes (PBNS) and density based Navier-stokes (DBNS) solves, were comparing. The results found that the mesh independent solutions are indistinguishable from one to another. However, the PBNS solver requires significantly higher mesh densities and longer time in order to resolve 
detail flow feather such as the chain of shocks that occur in the interior flow [10].

Considering above discusses, the authors adopt the DBNS solve, but there is something must do in the grid generation in order to reduce the computation time and improve efficiency.

\section{B. Turbulence model}

In this section, the other factors need to be mentioned is the selection of the turbulence model. Previous CFD studies have highlighted the important roles of an appropriate choice of the turbulence model in any accurate CFD analysis of supersonic flow in the inlet. Even so, there are currently some debate about the best choice of a turbulence model for such flow, with the accuracy of a range of models, such as Renormalizationgroup (RNG) k-e, Reynolds stress model (RSM), and so on [11].Some researchers suggest the accurate research in an emphasis region will include the effects of boundary layer bleed, or use of k-omega SST model. However, very recently comparisons between CFD and experiments have shown that the standard k-e is capable of predict accurately the interior flow global preference indicates [12].

The standard k-e model equations, including turbulent energy transport equation and equation of energy dissipation transport are outlined as follows [10]:

$$
\begin{gathered}
\frac{\partial \rho k}{\partial t}+\frac{\partial}{\partial x_{j}}\left[\rho u_{j} \frac{\partial k}{\partial x_{j}}-\left(\mu+\frac{\mu_{\tau}}{\sigma_{k}}\right) \frac{\partial k}{\partial x_{j}}\right] \\
=\tau_{t i j} S_{i j}-\rho \varepsilon+\phi_{k} \\
\frac{\partial \rho \varepsilon}{\partial t}+\frac{\partial}{\partial x_{j}}\left[\rho u_{j} \varepsilon-\left(\mu+\frac{\mu_{\tau}}{\sigma_{\varepsilon}}\right) \frac{\partial \varepsilon}{\partial x_{j}}\right] \\
=C_{\varepsilon_{1}} \frac{\varepsilon}{k} \tau_{t i j} S_{i j}-C_{\varepsilon_{2}} f_{2} \rho \frac{\varepsilon^{2}}{k}+\phi_{\varepsilon}
\end{gathered}
$$

Where $\sigma_{k}$ and $\sigma_{\varepsilon}$ are constant, their values are 1.0 and 1.3, respectively, $C_{\varepsilon_{1}}$ and $C_{\varepsilon_{2}}$ are constant, their values are 1.45 and 1.95 , respectively, $f_{2}$ is decay function of near wall and its expression is shown in Eq. (6)

$$
f_{2}=1-0.3 \exp \left(-\left(\frac{\rho k^{2}}{\mu \varepsilon}\right)^{2}\right)
$$

$\phi_{\varepsilon}$ is wall item and its expression is shown in Eq. (7).

$$
\phi_{\varepsilon}=2 \mu \frac{\mu_{t}}{\rho}\left(\frac{\partial^{2} u_{s}}{\partial y^{2}}\right)^{2}
$$

\section{CAlCUlation Domain}

Because it is very clear that setting of computational domain is an important factor which affects the accuracy of CFD, the authors adopt two representative models, namely, the independent inlet model and projectile/inlet combination model in this paper. The analysis was carried out for the effectiveness of the computing model by comparing the results of calculation in the same initial condition separately. The results verify combination model's accuracy and precision [13-15]. Particularly, a diverter is required between inlet and projectile body is used to account for effusion of boundary layer airflow which drastic change along the projectile surface. Taking no account of attack angle effect, one of the inlets was used to analyze flow field. This kind of computational domain as shown in Fig.3:

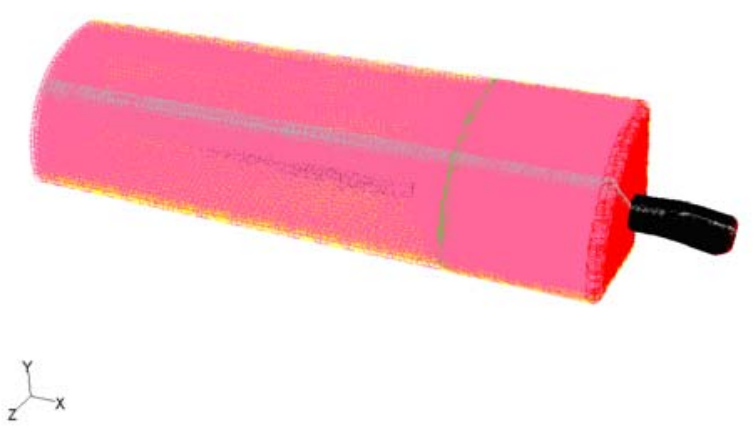

Figure 3. Single inlet grid generation

By coupling two parallel inlet models (Fig.4) with former one [16-17], the influence was taken into consideration effectively and the calculation time was reduced greatly compared with the regular method. The following figure shows the model of two parallel inlet grid generations.

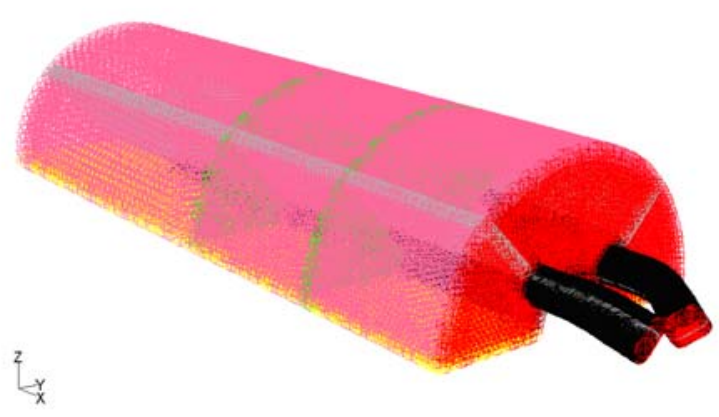

Figure 4. Two parallel inlet grid generations

It's very common encountered the divergence phenomenon in numerical simulation. And moreover, the fluid analysis process often cannot continue to study due to serious grid distortions, which causes by the improper quality of the grids [18-19]. All the above CFD grids were generated using the Gambit version 2.4.6 and built as multi-zone meshes in order to avoid this problem. In practice, the CFD software used in this paper was Fluent 6.3.26 which is developed by ANSYS Inc.

\section{RESUlTs AND DisCUSSIONS}

In order to understand accurately and realize each factor and their variety rules, this paper calculated a good many performance parameters under different work conditions, especially nearly the design point, analysis the 
total pressure, static temperature and other factors, which affect the performance parameters, synthetically evaluate the validity of the design, and propose qualitative rules between those affecting factors and performance parameters. Moreover, considering to quantify an inlet performance parameter, the variance ratio $(\Delta)$ can be defined as.

$$
\Delta=\frac{v a l_{d}-v a l_{c}}{v a l_{d}} \times 100 \%
$$

Where $\mathrm{val}_{d}$ is value of design points, $\mathrm{val}_{c}$ is value of a given operating condition.

\section{A. Ma number of incoming flow}

Ma number of incoming flow plays a very important role in performance parameters of inlet. The follow Table II lists the variance ratios of Ma number under different Ma number. The results of the numerical experimentation indicate that: 1$)$.The ratios are gradually smaller with the increasing of Ma number. This phenomenon can be explained by the design requirements, which it is assumed that the inlet has an optimal performance in the design points; 2). The ratios of inlet foreside are greater than the foreside one whether the mean Mach number or maximum Mach number.

TABLE II.

VARIANCE RATIOS OF MACH NUMBER UNDER A DIFFERENT MA NUMBER OF INCOMING FLOW

\begin{tabular}{|c|c|c|c|c|}
\hline \multirow{2}{*}{$\begin{array}{c}\text { Ma numbers } \\
\text { of incoming } \\
\text { flow }\end{array}$} & \multicolumn{2}{|c|}{$\begin{array}{c}\text { Variance ratio of mean } \\
\text { Mach number (\%) }\end{array}$} & \multicolumn{2}{c|}{$\begin{array}{c}\text { Variance ratio of } \\
\text { maximum Mach } \\
\text { number (\%) }\end{array}$} \\
\cline { 2 - 5 } & $\begin{array}{c}\text { Inlet } \\
\text { foreside }\end{array}$ & $\begin{array}{c}\text { Inlet } \\
\text { rear }\end{array}$ & $\begin{array}{c}\text { Inlet } \\
\text { foreside }\end{array}$ & $\begin{array}{c}\text { Inlet } \\
\text { rear }\end{array}$ \\
\hline 0.3 & 13.20 & 91.30 & 12.27 & 87.38 \\
\hline 0.5 & 13.05 & 87.32 & 12.21 & 85.99 \\
\hline 1.2 & 12.25 & 77.08 & 11.73 & 76.44 \\
\hline 2.0 & 11.20 & 57.46 & 11.10 & 43.54 \\
\hline 2.5 & 8.45 & 43.58 & 8.25 & 28.39 \\
\hline 3.0 & 4.30 & 30.72 & 3.90 & 14.03 \\
\hline 3.5 & 0.00 & 0.00 & 0.00 & 0.00 \\
\hline
\end{tabular}

In order to intuitive present that rules, the next four figures give the Mach number contours on the symmetry plane under the conditions of inflow Mach numbers 0.5, 1.2,2.5 and 3.5 respectively when the attack angle is zero. It is very clear that: 1).The Ma number distributions of the calculation domain are obviously different, especially in the subsonic and transonic case; 2). The different of Ma number between the foreside and rear of the inlet is a decrease with the increasing of $\mathrm{Ma}$ number. This phenomenon also shows the correctness of the previous conclusions. In particular, when airflow around the body shock wave occurs at the anterior point, which causes a sudden increase of entropy, static pressure, static temperature, density and the total enthalpy is unchanged after the shock. Thus, discontinuity appears as the corresponding decrease in velocity. Simultaneously, the first three oblique shock wave on the inlet compression surface converged in covering lip and no overflow when Mach number incoming flow equals 3.5.

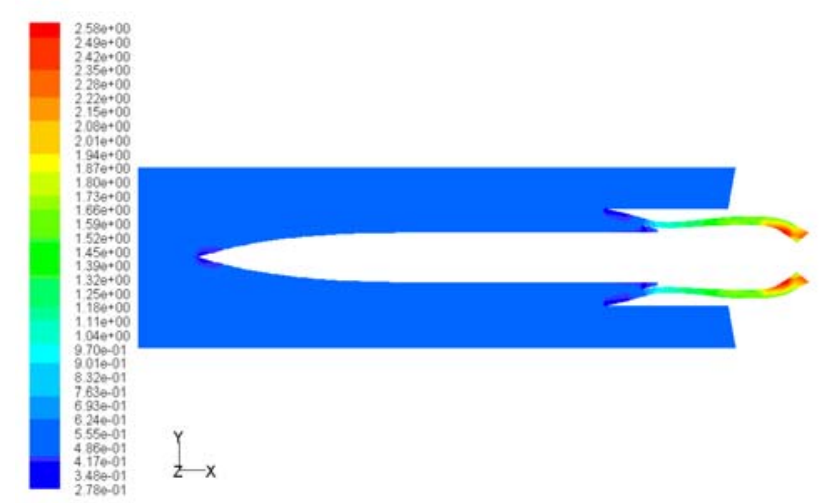

Figure 5. Mach number contours (incoming $\mathrm{Ma}=0.5$ )

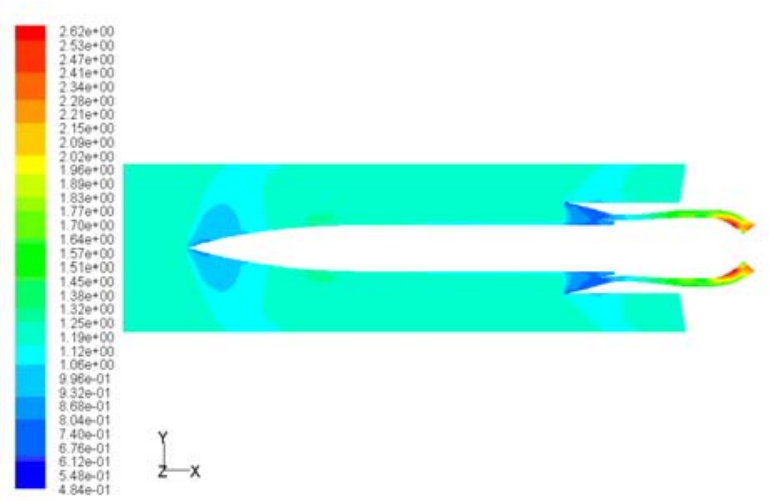

Figure 6. Mach number contours (incoming $\mathrm{Ma}=1.2$ )

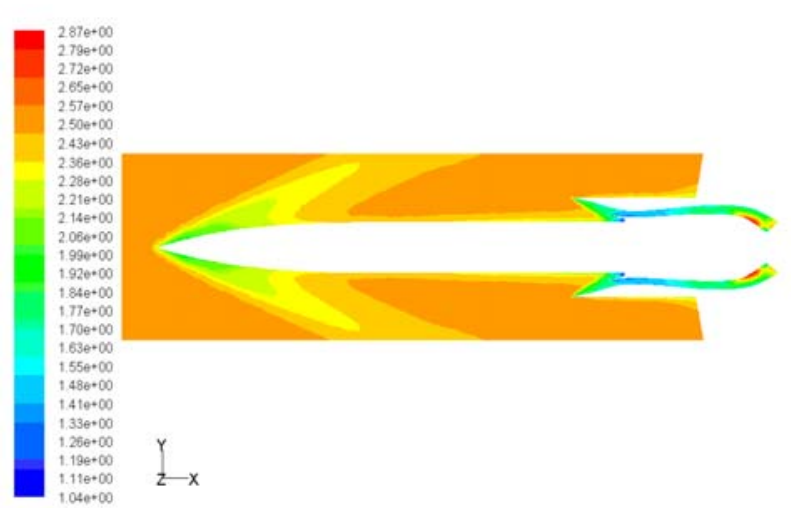

Figure 7. Mach number contours (incoming $\mathrm{Ma}=2.5$ )

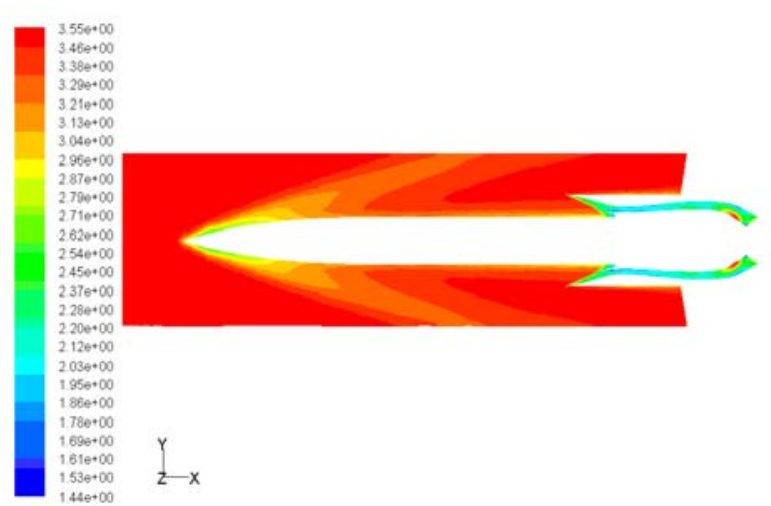

Figure 8. Mach number contours (incoming $\mathrm{Ma}=3.5$ ) 
The above results give the better illustration of rules between Ma number of incoming flow and variance ratios of Mach number in the inlet foreside and rear, but not enough to evaluate the inlet performance. The follow two tables give the variance ratios of pressure and temperature under different Ma number of incoming flow in order to justify the performance by cross-reference between the parameters. As it has shown in the following two tables, the results are consistent with the previous conclusions.

TABLE III.

VARIANCE RATIOS OF PRESSURES UNDER THE DifFERENT MA NUMBER OF INCOMING FLOW

\begin{tabular}{|c|c|c|c|c|}
\hline \multirow{2}{*}{$\begin{array}{c}\text { Ma numbers of } \\
\text { incoming flow }\end{array}$} & \multicolumn{2}{|c|}{$\begin{array}{c}\text { Variance ratio of static } \\
\text { pressure (\%) }\end{array}$} & \multicolumn{2}{c|}{$\begin{array}{c}\text { Variance ratio of total } \\
\text { pressure (\%) }\end{array}$} \\
\cline { 2 - 5 } & $\begin{array}{c}\text { Inlet } \\
\text { foreside }\end{array}$ & $\begin{array}{c}\text { Inlet } \\
\text { rear }\end{array}$ & $\begin{array}{c}\text { Inlet } \\
\text { foreside }\end{array}$ & $\begin{array}{c}\text { Inlet } \\
\text { rear }\end{array}$ \\
\hline 0.3 & 99.69 & 63.12 & 97.38 & 97.75 \\
\hline 0.5 & 99.64 & 61.47 & 96.97 & 97.49 \\
\hline 1.2 & 99.30 & 41.15 & 93.89 & 95.03 \\
\hline 2.0 & 98.06 & 19.26 & 82.39 & 85.29 \\
\hline 2.5 & 96.63 & 18.47 & 66.14 & 70.31 \\
\hline 3.0 & 95.09 & 17.04 & 42.07 & 42.62 \\
\hline 3.5 & 0.00 & 0.00 & 0.00 & 0.00 \\
\hline
\end{tabular}

TABLE IV

VARIANCE RATIOS Of TEMPERATURE UNDER THE DifFERENT MA NUMBER OF INCOMING FLOW

\begin{tabular}{|c|c|c|c|c|}
\hline \multirow{2}{*}{$\begin{array}{c}\text { Ma numbers of } \\
\text { incoming flow }\end{array}$} & \multicolumn{2}{|c|}{$\begin{array}{c}\text { Variance ratio of static } \\
\text { temperature (\%) }\end{array}$} & \multicolumn{2}{c|}{$\begin{array}{c}\text { Variance ratio of total } \\
\text { temperature (\%) }\end{array}$} \\
\cline { 2 - 5 } & $\begin{array}{c}\text { Inlet } \\
\text { foreside }\end{array}$ & $\begin{array}{c}\text { Inlet } \\
\text { rear }\end{array}$ & $\begin{array}{c}\text { Inlet } \\
\text { foreside }\end{array}$ & $\begin{array}{c}\text { Inlet } \\
\text { rear }\end{array}$ \\
\hline 0.3 & 64.89 & 36.68 & 70.40 & 71.27 \\
\hline 0.5 & 63.83 & 35.84 & 69.46 & 70.36 \\
\hline 1.2 & 56.11 & 27.11 & 62.62 & 63.72 \\
\hline 2.0 & 39.38 & 18.73 & 47.79 & 49.32 \\
\hline 2.5 & 26.38 & 16.34 & 34.76 & 36.67 \\
\hline 3.0 & 12.20 & 13.63 & 18.83 & 21.21 \\
\hline 3.5 & 0.00 & 0.00 & 0.00 & 0.00 \\
\hline
\end{tabular}

The quantification rules between the Ma number of incoming flow and total pressure recovery coefficients is shown in figure 9.It's can be seen in this figure that: 1).The total pressure recovery coefficient is increasing as the Ma number of incoming flow increases, and then is gradually decreased after the point of Mach number is equal to $0.5 ; 2$ ).All the total pressure recovery coefficient is greater than design requirement, so the design is successful;

As mentioned above paragraphs, a number of quantities can be used in assessing the inlet performance and the quality of the flow entering the combustion chamber [18]. These include total pressure recovery, distortion level, swirl, total temperature, velocity, and so on. However, one of the most important evaluation criteria is the mass flow. The figure 10 gives the dissimilar mass flows under different Ma number of incoming flow. It can be observed that: 1) The design intake's mass flow is greater than the design requirements and the design process is successful; 2) The mass flow is gradually larger with the increasing of Ma number, and moreover, change of mass flow is faster in the high Mach number conditions.

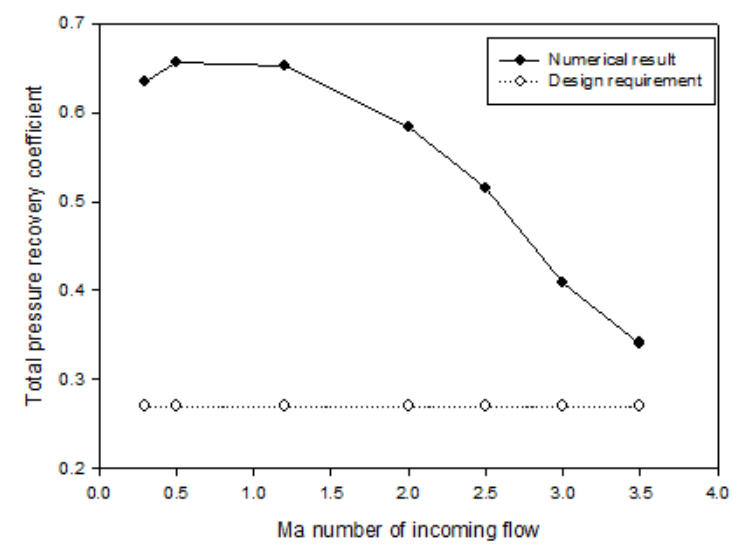

Figure 9. Relation between total pressure recovery coefficient and Ma number of incoming flow

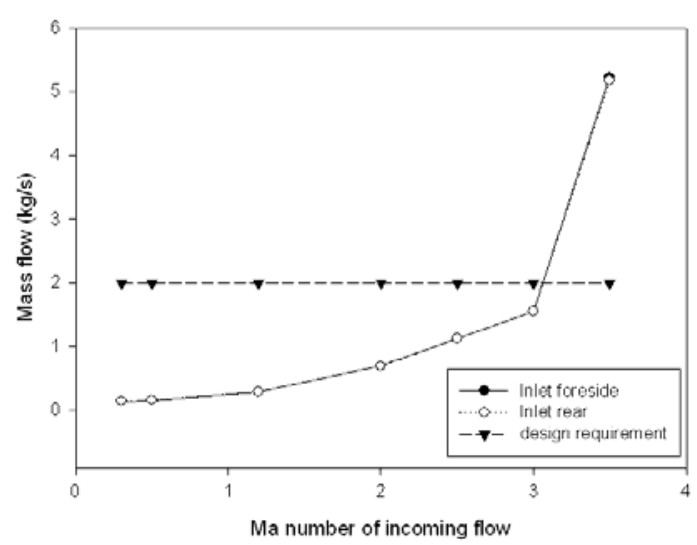

Figure 10. Mass flows under different Ma number of incoming flow

\section{B. Attack angle}

As mentioned previously, the analysis of the inlet is arranged in ' $X$ ' configuration and carried out for two models under the conditions of considering the attack angle. When inflow Mach number is 3.5, the effects of attack angle on Mach number are shown in the Table $\mathrm{V}$ and VI. It can be known that: 1). The Ma numbers of intake outlet are greater than the entrance one whether the mean Mach number or maximum Mach number; 2).The Ma numbers are the unapparent changes with the increasing of attack angle.

TABLE V.

MEAN Ma Number of INLET UNDER DifFERENT ATTACK ANGLES

\begin{tabular}{|c|c|c|c|c|}
\hline \multirow{2}{*}{$\begin{array}{c}\text { Attack } \\
\text { angles } \\
\text { (deg) }\end{array}$} & \multicolumn{2}{|c|}{$\begin{array}{c}\text { Mean Ma numbers of } \\
\text { intake entrance }\end{array}$} & \multicolumn{2}{|c|}{$\begin{array}{c}\text { Mean Ma numbers of } \\
\text { intake outlet }\end{array}$} \\
\cline { 2 - 5 } & $\begin{array}{c}\text { windward } \\
\text { side }\end{array}$ & $\begin{array}{c}\text { leeward } \\
\text { side }\end{array}$ & $\begin{array}{c}\text { windward } \\
\text { side }\end{array}$ & $\begin{array}{c}\text { Leeward } \\
\text { side }\end{array}$ \\
\hline 2 & 0.21 & 0.22 & 3.16 & 3.21 \\
\hline 3 & 0.21 & 0.21 & 3.11 & 3.18 \\
\hline 5 & 0.20 & 0.21 & 3.02 & 3.12 \\
\hline 7 & 0.19 & 0.22 & 2.93 & 3.05 \\
\hline
\end{tabular}


TABLE VI.

MAXIMUM MA NUMBER OF INLET UNDER DifFERENT ATTACK ANGLES

\begin{tabular}{|c|c|c|c|c|}
\hline \multirow{2}{*}{$\begin{array}{c}\text { Attack } \\
\text { angles } \\
\text { (deg) }\end{array}$} & \multicolumn{2}{|c|}{$\begin{array}{c}\text { Maximum Ma numbers } \\
\text { of in take entrance }\end{array}$} & \multicolumn{2}{|c|}{$\begin{array}{c}\text { Maximum Ma numbers } \\
\text { of intake outlet }\end{array}$} \\
\cline { 2 - 5 } & $\begin{array}{c}\text { windward } \\
\text { side }\end{array}$ & $\begin{array}{c}\text { leeward } \\
\text { side }\end{array}$ & $\begin{array}{c}\text { windward } \\
\text { side }\end{array}$ & $\begin{array}{c}\text { Leeward } \\
\text { side }\end{array}$ \\
\hline 2 & 0.29 & 0.27 & 3.49 & 3.48 \\
\hline 3 & 0.25 & 0.27 & 3.50 & 3.47 \\
\hline 5 & 0.25 & 0.27 & 3.50 & 3.44 \\
\hline 7 & 0.23 & 0.28 & 3.51 & 3.40 \\
\hline
\end{tabular}

One of the advantages of CFD is the visualization. The results are quite obvious when reviewing simulations. The following four figures give the Mach number contours on the symmetry plane under a different attack angle when inflow Mach number is 3.5. From those figures, we can come to the conclusion that: 1) The existence of attack angle breaks the symmetry of the shock wave which occurs at the anterior point and the angle between wave and inlet axis increases as an increase of attack angle; 2) When the airflow through the shock the flow direction is changed and airflow is more complicated after the wave; 3) With the increasing attack angle, the internal shock wave is pushed forward to approach the inlet lip gradually;4).the Shock wave of inlet entrance no longer converged in covering lip, and produce overflow. In addition, bump is appeared in the internal inlet, and the detached phenomenon is obvious at the bottom of the entrance.

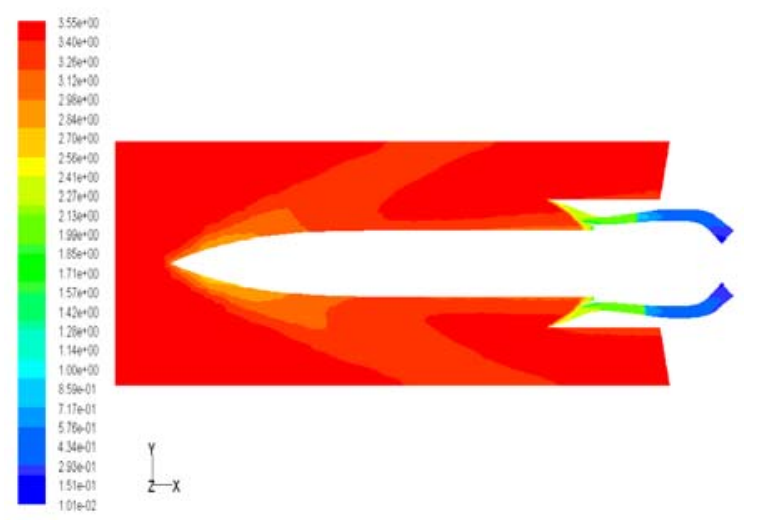

Figure 11. Mach number contours (attack angle =2 deg)

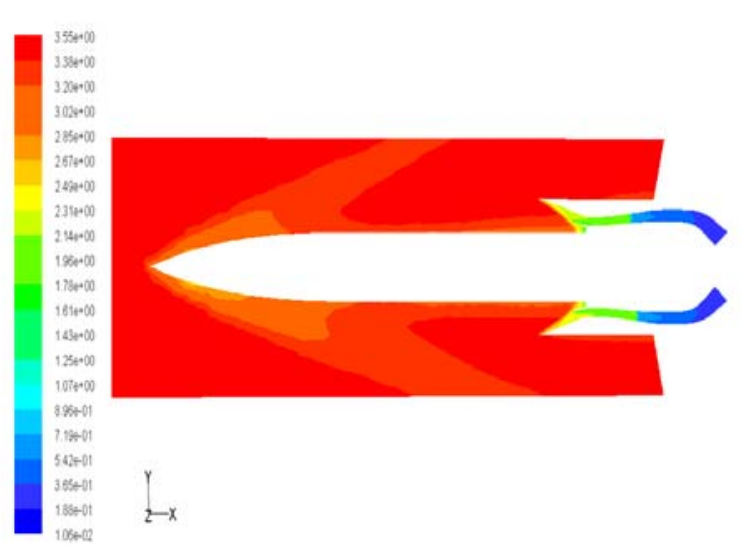

Figure 12. Mach number contours (attack angle =2 deg)

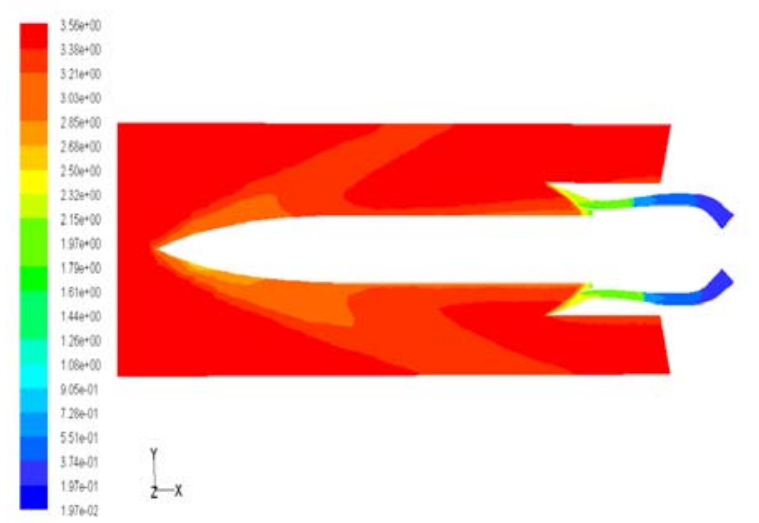

Figure 13. Mach number contours (attack angle =2 deg)

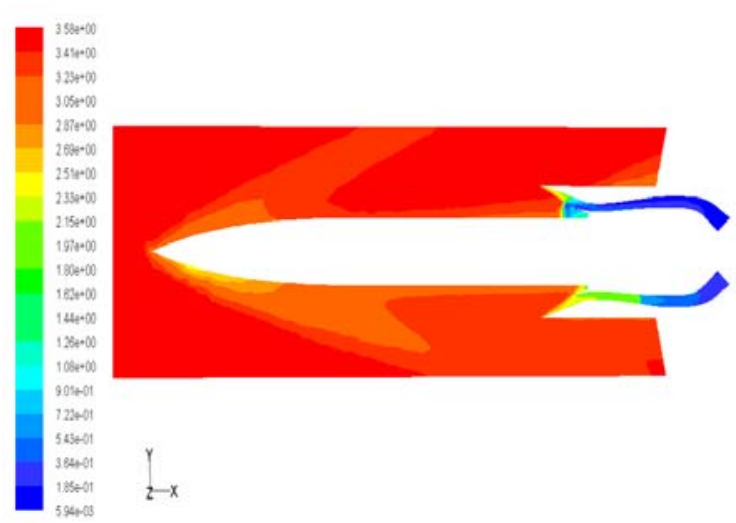

Figure 14. Mach number contours (attack angle =2 deg)

In order to evaluate the inlet performance, the Table VII and VIII list the total pressure and total temperature values under the different attack angle. As it has shown in the following two tables, the results are consistent with the previous conclusions.

TABLE VII.

TOtAl PREsSURe of INLET UNDER DifFERENT ATTACK ANGLES

\begin{tabular}{|c|c|c|c|c|}
\hline \multirow{2}{*}{$\begin{array}{c}\text { Attack } \\
\text { angles } \\
\text { (deg) }\end{array}$} & \multicolumn{2}{|c|}{$\begin{array}{c}\text { Total pressure of intake } \\
\text { entrance }\end{array}$} & \multicolumn{2}{c|}{$\begin{array}{c}\text { Total pressure of intake } \\
\text { outlet }\end{array}$} \\
\cline { 2 - 5 } & $\begin{array}{c}\text { windward } \\
\text { side }\end{array}$ & $\begin{array}{c}\text { leeward } \\
\text { side }\end{array}$ & $\begin{array}{c}\text { windward } \\
\text { side }\end{array}$ & $\begin{array}{c}\text { Leeward } \\
\text { side }\end{array}$ \\
\hline 2 & 267895.25 & 267258.44 & 572111.50 & 608622.81 \\
\hline 3 & 266652.59 & 267139.78 & 555314.88 & 607583.56 \\
\hline 5 & 266109.03 & 267114.50 & 559965.19 & 607825.63 \\
\hline 7 & 261825.47 & 267392.91 & 609845.50 & 607979.63 \\
\hline
\end{tabular}

TABLE VIII.

TOTAL TEMPERATURE OF INLET UNDER DifFERENT ATTACK ANGLES

\begin{tabular}{|c|c|c|c|c|}
\hline \multirow{2}{*}{$\begin{array}{c}\text { Attack } \\
\text { angles } \\
\text { (deg) }\end{array}$} & \multicolumn{2}{|c|}{$\begin{array}{c}\text { Total temperature of in } \\
\text { take entrance }(\mathrm{K})\end{array}$} & \multicolumn{2}{|c|}{$\begin{array}{c}\text { Total temperature of } \\
\text { intake outlet }(\mathrm{K})\end{array}$} \\
\cline { 2 - 5 } & $\begin{array}{c}\text { windward } \\
\text { side }\end{array}$ & $\begin{array}{c}\text { leeward } \\
\text { side }\end{array}$ & $\begin{array}{c}\text { windward } \\
\text { side }\end{array}$ & $\begin{array}{c}\text { Leeward } \\
\text { side }\end{array}$ \\
\hline 2 & 746.33 & 746.30 & 746.27 & 746.27 \\
\hline 3 & 746.30 & 746.30 & 746.27 & 746.28 \\
\hline 5 & 746.30 & 746.30 & 746.27 & 746.28 \\
\hline 7 & 747.67 & 746.33 & 746.13 & 746.29 \\
\hline
\end{tabular}

Figure 14 depicts a mass flow of an inlet under various attack angles when inflow Mach number equals 3.5. The 
results of the numerical experimentation indicate that: 1).Due to the effects of attack angle, all the mass flow does not meet the design requirement; 2) In the condition of attack angles is two degrees, the discrepancy between a calculative values and design requirements is unapparent, so this design can be applied to small attack angle, which the angle is less than two degrees.

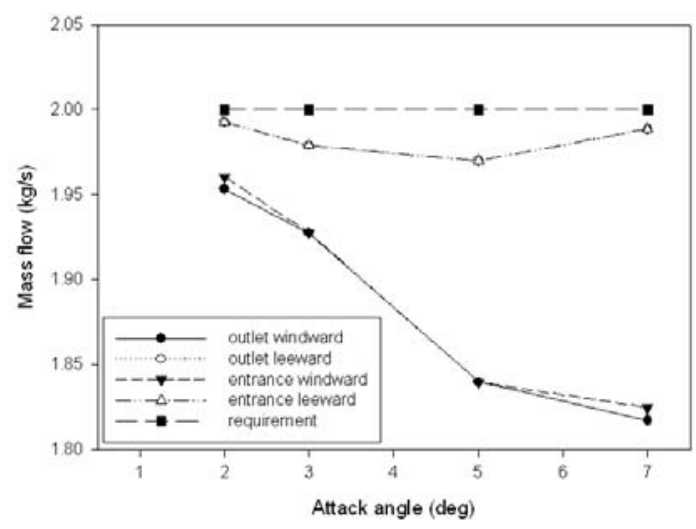

Figure 15. Mass flows under different attack angle

\section{Altitude}

The influence of altitude must be taking into account in practice. The Table IX lists the variance ratios of mean Ma numbers and the maximum Ma numbers. From this table, the variance ratio in the outlet has the acute changed with increasing of altitudes clearly, but its corresponding values degrade sharply in the entrance.

TABLE IX.

MA NUMBER OF INLET UNDER DIFFERENT ALTITUDES

\begin{tabular}{|c|c|c|c|c|}
\hline \multirow{2}{*}{$\begin{array}{c}\text { Altitude } \\
(\mathrm{Km})\end{array}$} & \multicolumn{2}{|c|}{$\begin{array}{c}\text { Variance ratio of mean } \\
\text { Ma numbers (\%) }\end{array}$} & \multicolumn{2}{|c|}{$\begin{array}{c}\text { Variance ratio of } \\
\text { maximum Ma numbers } \\
(\%)\end{array}$} \\
\cline { 2 - 5 } & $\begin{array}{c}\text { intake } \\
\text { outlet }\end{array}$ & $\begin{array}{c}\text { intake } \\
\text { entrance }\end{array}$ & $\begin{array}{c}\text { intake } \\
\text { outlet }\end{array}$ & $\begin{array}{c}\text { intake } \\
\text { entrance }\end{array}$ \\
\hline 16 & 62.82 & 0.92 & 76.85 & 0.08 \\
\hline 14 & 47.93 & 0.58 & 53.65 & 0.05 \\
\hline 10 & 0.00 & 0.00 & 0.00 & 0.00 \\
\hline
\end{tabular}

Considering the data creditability, the authors present the variance ratios of the temperature and the mass flow in the Table X and XI. From those tables, we can come to the conclusion that: 1).The temperature is an unremarkable change with the increasing altitudes; 2). The variance ratios of mass flow have the biggish values under different altitudes. However, this inlet preference still meets the requirement.

TABLE $X$.

TEMPERATURE OF INLET UNDER DIFFERENT ALtITUDES

\begin{tabular}{|c|c|c|c|c|}
\hline \multirow{2}{*}{$\begin{array}{c}\text { Altitude } \\
(\mathrm{Km})\end{array}$} & \multicolumn{2}{|c|}{$\begin{array}{c}\text { Variance ratio of static } \\
\text { temperature (\%) }\end{array}$} & \multicolumn{2}{|c|}{$\begin{array}{c}\text { Variance ratio of total } \\
\text { temperature (\%) }\end{array}$} \\
\cline { 2 - 5 } & $\begin{array}{c}\text { intake } \\
\text { outlet }\end{array}$ & $\begin{array}{c}\text { intake } \\
\text { entrance }\end{array}$ & $\begin{array}{c}\text { intake } \\
\text { outlet }\end{array}$ & $\begin{array}{c}\text { intake } \\
\text { entrance }\end{array}$ \\
\hline 16 & -6.30 & 1.43 & 2.15 & 2.93 \\
\hline 14 & -4.97 & 2.01 & 2.05 & 2.96 \\
\hline 10 & 0.00 & 0.00 & 0.00 & 0.00 \\
\hline
\end{tabular}

TABLE XI.

MASS FLOW OF INLET UNDER DifFERENT ALTITUdES

\begin{tabular}{|c|c|c|}
\hline $\begin{array}{c}\text { Altitude } \\
(\mathrm{Km})\end{array}$ & $\begin{array}{c}\text { Variance ratio of mass } \\
\text { flow in outlet (\%) }\end{array}$ & $\begin{array}{c}\text { Variance ratio of mass } \\
\text { flow in entrance (\%) }\end{array}$ \\
\hline 16 & 60.63 & 60.64 \\
\hline 14 & 45.97 & 45.97 \\
\hline 10 & 0.00 & 0.00 \\
\hline
\end{tabular}

\section{Results AND Discussions}

Based on the basic characteristic of the inlet and considering the design requirements of solid rocket ramjet assisted range projectile, the two-dimensional supersonic projectile inlet was designed and verified by numerical simulation. The results are shown that:

1) The design process is successful, but the working conditions should be limited to the small angle of attack;

2) The total pressure recovery coefficient is increasing as the Ma number of incoming flow increases, and then is gradually decreased after the point of Mach number is equal to 0.5 ;

3) The existence of attack angle reduces values of total pressure recovery. And moreover, the shock wave which occurs at the anterior point is gradually deviating from projectile body direction with the increase of attack angle;

4) There are four shock waves on the compression surface and with the increasing attack angle the last one is pushed forward to approach the inlet lip gradually;

5) The variance ratio in the outlet has the acute changed with increasing of altitudes clearly, but its corresponding values degrade sharply in the entrance.

\section{ACKNOWLEDGMENT}

The authors are grateful to the natural science fund of the Inner Mongolia autonomous region (200508010705) and the science and technology on combustion, internal flow and thermo-structure laboratory of northwestern polytechnical university for their support.

\section{REFERENCES}

[1] D. A. Ault, D. M. Wee, "Experimental and computational results for the external flow field of a scramjet Inlet," Journal of Propulsion and Power, vol. 4, pp. 178-193, 1994.

[2] P. Safaris, A. Polka, "Optimal shock wave parameters for supersonic inlets," Journal of Propulsion and Power, vol. 12, no. 1, pp.21-25, 1996.

[3] W.Wang, L.K. Cui, Z.Li, "Design and study of twodimensional supersonic projectile inlet”, SMSME2011, Wuhan: IEEE Press. 2011

[4] R. D. Richtmyer, K. W. Morton, Difference Methods for Initial-value problem, New York: Interscience, 1967.

[5] G. Chesshire, W. D. Henshaw, "Composite overlapping meshes for the solution of partial differential equations". Journal of Computational Physics, no. 90,pp1-64,1990,

[6] Y.Z. Zhang, Z. Li and H. L. Li, "Three-dimensional numerical simulation of afterburner flow field of solid rocket ramjet”, Aeroengine, vol. 35, no. 3, pp.22-26, 2009 (in Chinese). 
[7] K. Oswatisch, "Pressure recovery in missiles with reaction propulsion at high supersonic speeds”, NACA, TM1140, 1947.

[8] S. B. Luo, W. C. Luo, M. Ding, et al, "The multi-level and multiobjective optimization design method for two dimensional scramjet inlet”, Journal of National University of Defense Technology, vol. 26, no. 3, pp.1-6, 2004 (in Chinese).

[9] H.K.Versteeg, W. Malalasekera. An introduction to computational fluid dynamics: the finite volume method,1st ed. Pearson Prentice,1995

[10] J. D. Anderson, Computational fluid dynamics: the basics with applications, New York: McGraw-Hill companies Inc, 1995

[11] Y. Bartosiewicz, Z. Aidoun, Y Mercadier, ”Numerical assessment of ejector operation for refrigeration applications based on CFD”,Appl Therm Eng 2006,26(56):604-12

[12] A. Hemidia, F. Henry, J-M. Seynhzeve, Y. Bartosiewicz. "CFD analysis of a supersonic air ejector: part I: experimental validation of single-phase and two-phase operation”, Appl Therm Eng2009,29:1523-31

[13] X. J. Zhang, D. W. Liang, "Performance effects of geometry parameters on hypersonic inlet ,"Journal of Nanjing University of Aeronautics \& Astronautics, vol. 37, no. 6, pp.685-689, 2005 (in Chinese).

[14] W. Wang , Z. Li and H. L. Li, et al, "The numerical simulation of a solid ramjet engine inlet base on fluent", Journal of Sichuan university(Engineering Science Edition) ,vol. 40, pp.83-85, 2008 (in Chinese).

[15] S. Y. Zhang, Y. Z. Bai, "Numerical simulation and analysis for 2-D supersonic inlet," Journal of Projectiles,
Rockets, Missiles and Guidance, vol. 28, no. 3, pp.203205+209, 2008 (in Chinese).

[16] X. Z. Liu, C. M. Zhang, Power plant of cruise missile, Beijing: Aerospace Press, 1992 (in Chinese).

[17] W. Q. Pan, Engineering fluid mechanics, Beijing: Tsinghua University Press, 1990 (in Chinese).

[18] M.J. Ostrander, M.E. Thomas, J.B. Clegern. "Inlet analysis for ATR-Powered Supersonic Missile”. AIAA-95-2805

[19] J.H. Ferziger, M. Peric. Computational Methods for Fluid Dynamics, third rev edition, New York: Springer, 2002

Wei Wang received the Master of General and Fundamental Mechanics in 2010.

He is a full-time PhD student in Northwestern Polytechnical University at present.

During his doctor study, His research interests include modeling and simulation.

Likun Cui received the Master of Solid Mechanics in 2004.

$\mathrm{He}$ is a full-time $\mathrm{PhD}$ student in Inner Mongolia University of Technology at present.

During his doctor study, His research interests include finite element and neural network.

Zhuo Li received the $\mathrm{PhD}$ degree from the Tsinghua University.

$\mathrm{He}$ is currently the researcher of the Inner Mongolia University of Technology. His main research interests include solid mechanics, fluid mechanics and numerical calculation. 